\title{
Educated Side by Side: The Role of Language in the European Schools
}

Language learning and intercultural communication are at the core of the European schools' genesis and ethos. The schools are a success story in that the European schools' network continues to grow. Graduates are not only proficient in their L1, but have achieved a sufficient degree of fluency in an L2 to have successfully studied content subjects such as history through their L2 and sometimes their L3. All European schools' students study an L3. Students work and learn with and from teachers and other students who come from diverse nationalities. Longstanding structural arrangements such as the organisation of the teaching of a minimum of three languages including the L1, the right to establish L1 language sections where numbers warrant it, the requirement to study some subjects through an L2, and the mixing of students from diverse nationalities have all helped school graduates to work side by side and become multilingual. The chapter recognises this success, but will above all explore ways to bring greater clarity and substance to the European schools' current organisation of learning to enhance language learning and the development of intercultural competence. The previously discussed premise of a curriculum, which includes an intelligible set of specifications expressed as learning standards or objects, as the principal driver of educational reform will serve as a key lens for the discussion. 


\section{Language Policy}

Language policy elements are to be found in numerous European schools' policy prescriptions (e.g. mission statement, General Rules of the European Schools, Provision of Educational Support in the European Schools - procedural document, Reform of the European Schools System, Proposal of the 'Organisation of Studies in the Secondary Cycle' Working Group, Control of the Level of Linguistic Competence as Part of the Procedure for Recruitment of Non-native Speaker Teaching and Educational Support Staff, Languages of Tuition for Economics in the European Schools System, and language and content subject syllabuses). Policy is also being developed in situ through the interpretation of existing policies (e.g. discussions of whether and in which school in Brussels an Estonian language section will be opened). The policy is embodied in and realised through a series of mechanisms or structural arrangements: language sections that support learning through the L1 in cases where the number of students is sufficient; special provisions for SWALS; the obligatory delivery of some content subjects through the students' L2 (and possibly L3); and language courses in L1, L2, L3, L4 and L5.

Despite the fact that language learning and intercultural communication are at the core of the European schools' ethos, there is no one place the European schools' internal and external stakeholders can turn to for understanding the nature of multilingual education in the European Schools, for an overview of the aims of language learning, or for direction on how language policy translates into teaching and learning practices. Existing policy documents including curriculum documents provide scant direction on how teaching and learning practices at the European schools are expected to promote high degrees of language learning, or content and language learning whilst learning through a first, second and third language.

Typically bilingual education supports individuals in becoming and remaining bilingual. At least two languages are used to teach different content subjects such as mathematics or history for several years. Languages are also taught in language classes. If students are to be well placed in continuing to develop their second and first language proficiency after graduation both languages would be used as media of instruc- 
tion throughout the final years of school life. Bilingual education aims to support students in developing age and grade-appropriate levels of:

- L1 competence in reading, writing, speaking, and listening;

- advanced functional proficiency in L2 reading, writing, speaking and listening;

- academic achievement in all school content subjects, such as Mathematics and Science taught primarily through the L2 and in those taught primarily through the L1;

- levels of understanding and appreciation of the culture of the L1 group, and of the L2 group(s); and, promotes

- capacity for and interest in inter-cultural communication (Mehisto 2012).

A bilingual education programme can support students in learning additional languages; however, it would not be referred to as a trilingual or multilingual education programme if students were not afforded an opportunity to learn content subjects through three or more languages. Thus, the European schools can be considered above all a bilingual education system that seeks to foster multilingual proficiency among its graduates.

In general, languages are considered interdependent. Students are likely to transfer L1 skills and knowledge to their L2 and L3 and vice versa. The greater a student's L1 proficiency, the greater his or her metalinguistic awareness, and the better his or her L1 language learning habits and skills, the more likely it is that this proficiency, metalinguistic awareness and these language learning habits and skills will support the learning of the L2 and the L3 and through the L2 and L3 (cf. Cummins 1997, 2013). Moreover, 'cognition and language create each other' (Ellis and Robinson 2008). This means that deeper order thinking and meaning making are also dependent 'on the development of advanced literacy skills' (Cammarata et al. 2016). Hence bilingual education is expected to focus on the development of high degrees of literacy skills in both the L1 and the L2. In order to support the development of high degrees of biliteracy successful bilingual education programmes foster cooperation between teachers teaching through the students' L1 and L2 (Genesee and Hamayan 2016). 
The lack of a European Schools' overarching language policy document is problematic at both the systemic and classroom levels. It implies that bilingual and multicultural education are not being led in a systematic manner with clearly stated goals. A key characteristic of successful bilingual education systems is having a well-defined purpose, goals, standards and plans pertaining to both content and language learning and this in all classes. Cloud et al. (2000: 10) argue that these must all be '(a) understood, (b) accepted, and (c) implemented in a coherent fashion by all educational and support personnel in the programme'. This aligns with Fullan's (2001) previously discussed view that it is essential to have high degrees of coherence across vision statements, plans and polices, and this in particular during an education reform effort. Moreover, the lack of a language policy document suggests that there is no concerted effort to help all educators (no matter the language of instruction) to understand the specificities of working in a bilingual education context. Commonly held knowledge by school staff of these specificities is considered a hallmark of successful bilingual education systems (Fortune and Tedick 2014). Teachers need to understand how pedagogy changes in bilingual education contexts. For example, all teachers are expected to support content and language learning, but content teachers on several continents have difficulty assuming the dual role of teaching both content and language (Gajo 2007; Genesee 2008), while language teachers often find it difficult to use a content-based approach (Martel 2016). In other words, the pedagogical principles are not self-evident, and in particular secondary school teachers tend not to be prepared to apply best practices in bilingual education without first receiving considerable training and support. In addition, the theoretical equality of esteem accorded to all official EU languages at the European schools is in practice not fully achieved. Some languages, such as the three official ones, English, French and German, enjoy greater status than others. Not all parents fully appreciate the value of educating their children through their L1.

In order to help address some of the above concerns, a language policy, we suggest, could include some or all of the following elements: an introduction or preamble; aims; connections to European School values and other policies; a description of the role of language learning (including for L1, L2, L3, L4 and L5); in-class and out-of-class language use in 
classes taught through the L1 and L2; in-class and out-of-class language use in mixed language groups; core pedagogical principles; core intercultural competences; management implications; student support services; staff support services; staff professional development; student assessment; measures for raising awareness of language issues; an explanation of how and when the policy will be reviewed; and a glossary of key terms (e.g. bilingualism, trilingualism, multilingualism, plurilingualism, multilingual teaching, multicultural education, intercultural competence).

More specifically, for example, in relation to pedagogical principles, the policy would provide details of core practices that all teachers would be expected to apply. These might include the requirement to integrate content and language instruction in all classes through the concurrent articulation of clear, explicit and visible intended content and language learning objectives/outcomes, and the regular analysis of progress made in achieving these objectives. This analysis would involve the use of assessment as a tool for learning content and language, and for supporting students in developing related learning skills. The ultimate purpose of helping students to become assessment literate in reference to content and language learning is to contribute to their development as engaged and autonomous learners of both. The co-construction of learning environments by teachers and students that are safe, supportive and engaging, and that encourage rich verbal and written student output would also be a common practice in bilingual education as students need support in managing the added stress and cognitive load of learning through additional languages. The concurrent scaffolding of both content and language learning, and critical thinking is one means for achieving this. Finally, the use of differentiation, including for enrichment, for students at various stages on their content and language learning pathways would be a vital policy element particularly in the European schools with their diverse and somewhat transient student populations.

With regards to managing language practices, the proposed language policy, we suggest, could articulate guiding principles such as: expectations regarding content learning and bilingualism, trilingualism and/or multilingualism as they relate to school principals, teachers, and students; a commitment to build actively the status of all school languages; the expectation that all teachers are teachers of both content and language, 
and that management practices (e.g. professional development, performance reviews, inspections) support teachers in assuming this dual role; a commitment to ensure that the language needs of each student will be assessed in order to develop, as required, individual learning pathways; and that assessment for learning will be used to support content and language learning in all classes including those taught through the L1. Finally, this part of the policy could describe mechanisms that will be used to encourage language and content teachers to co-operate, and for teachers to co-operate across languages.

How any such policy is developed and approved will also be central to whether it will be well understood, accepted and implemented. Following on from the discussion in Chap. 1, if this change is to have the desired impact, the policy would need to be developed through a stakeholder inclusive process with external advice from language education experts. The policy would need to be widely discussed and communicated so key stakeholders were aware of, understood and supported it. The policy would need to become part of the work culture meaning that it is discussed in planning meetings and progress in implementation is systematically evaluated and reported on. Policy-related short and long-term wins would need to be identified and celebrated. Finally over time, the policy should be revised and enhanced to ensure it is fit for purpose and that stakeholders remain committed to its implementation.

\section{Intercultural Competence}

It is the mission of the European Schools to provide 'a multilingual and multicultural education for nursery, primary and secondary level students' that should, according to Jean Monnet's 1953 vision, help 'bring into being a united and thriving Europe'. Monnet's vision implies a high expectation where Europeans work side by side across languages and cultures to build a united and thriving Europe; however, the terms multilingual and multicultural are not defined by the European Schools. The definition of these and other related terms reveal that developing proficiency in a language is inextricably tied to the development of intercultural competence. 
The Commission of the European Communities (European Commission 2007: 6) defines multilingualism as 'the ability of societies, institutions, groups and individuals to engage, on a regular basis, with more than one language in their day-to-day lives'. The European Commission (2005: 3) also refers to multilingualism as the co-existence of different language communities in one geographical area'. Thus, for the European Commission (EC) multilingualism focuses on the co-existence of and the regular engagement with more than one language in one territory. Language is not problematised, but rather it is presented as a positive, or, at the very least, neutral force in the co-existence of people at an individual, group, institutional and societal level. This broad definition embraces both the concepts of multilingualism and plurilingualism as defined by the Council of Europe, which makes a distinction between multilingualism as a description of social organisation, and plurilingualism as an individual linguistic and cultural competence in more than one language and culture. The Council of Europe defines plurilingualism as the ability:

to use languages for the purposes of communication and to take part in intercultural action, where a person, viewed as a social agent, has proficiency, of varying degrees, in several languages and experience of several cultures. This ability is concretised in a repertoire of languages a speaker can use. (Council of Europe 2007a: 17)

This definition stresses the ability and the responsibility of the plurilingual individual to bridge the multilingual social order. A plurilingual individual is not only defined in linguistic terms, but is considered capable of crossing both a linguistic and cultural divide, having linguistic and cultural competences that are evidenced by intercultural communication and enrichment. Plurilingual co-existence includes a process of crossfertilisation or 'intercultural action' (ibid.).

The language learner becomes plurilingual and develops interculturality. The linguistic and cultural competences in respect of each language are modified by knowledge of the other and contribute to inter-cultural awareness, skills and know-how. They enable the individual to develop an enriched, more complex personality and an enhanced capacity for further language learning and greater openness to new cultural experiences. (Council of Europe 2007b: 43) 
This definition includes social and intercultural competences that are an essential element of communication through different languages. The same can be assumed for the European Commission's definition of multilingualism. Language and intercultural skills are central to the European project. The European Union has established a goal of 'mother tongue plus two other languages for all' its citizens (European Commission 2003: 7). Moreover, the European Commission (2017) has recently reiterated the need to develop a new narrative that stresses that 'the EU is not solely about the economy and growth, but also about cultural unity and common values in a globalised world.' This signals a possible shift away from euro-centric intercultural competence to a more global view of multilingual and intercultural competence. This aligns with the findings of Eccles and Gootman (2002), who argue that, in an era of globalisation, indepth knowledge of more than one culture is considered a vital part of the cognitive development of young people.

The fact that the European Schools have not defined key terms such as multilingualism or culture, or drawn out what constitutes intercultural competence, does not appear to have deterred support for the schools. Parents have praised 'the multicultural and European citizen spirit brought by the multilingual education of European Schools' as one of its most appreciated features (Leaton Gray et al. 2015: 10). The number of schools in the network continues to grow. It is generally assumed that multilingual education is the vehicle 'of intercultural education' and 'that acquiring a deep knowledge and an active command of languages other than one's mother tongue has the effect of expanding the mind and enhancing intercultural competence' (Allemann-Ghionda 2012: 126). The assumption implies that intercultural competence may be an incidental side effect of multilingual education. A review of a cross-section of the European Schools curriculum documents confirms that culture and intercultural competences have not been defined in detail in any given subject curriculum or in a school wide policy document (Leaton Gray et al. 2015). However, the fact that history and geography are taught as of the third year of secondary school in the students' L2 by teachers who most likely do not share their nationality does at least create an opportunity to foster a broadening of the students' ability to view issues from different perspectives (an intercultural competence). Still, 
the decisions on what constitutes intercultural competence, and whether, and if so how, it should be explicitly taught appear to be left to individual teachers.

We suggest that by centrally defining terms such as culture or at the very least including an exploration of several definitions of the term culture, the European schools would be better placed to support students and teachers in developing a substantially richer understanding of the term, which in turn could contribute to a more nuanced understanding of intercultural competence. UNESCO (2001) defines culture in its Universal Declaration on Cultural Diversity as follows:

Culture is the set of distinctive spiritual, material, intellectual and emotional features of society or a social group, and that it encompasses, in addition to art and literature, lifestyles, ways of living together, value systems, traditions and beliefs. (UNESCO 2001)

The above definition along with a review of other well-known definitions could serve as a reference point in exploring elements of culture. For example, in order to help students to engage with culture as a concept and to deepen their cultural knowledge all subject curricula could draw to a lesser or greater extent on some of the following often interrelated categories - abandoned practices, architecture, art (fine and applied), attitudes, beliefs, concepts of the universe, cuisine, custom, education, emigration, environmental protection, events, experience, famous people, film, friendship, games, hierarchies, history, humour, immigration, informal governing arrangements, insults, knowledge, legislation, literature, material objects/artefacts, media, music, notions of time, personal space, politics, politeness, possessions, practices, prejudice, proverbs, public institutions, queuing, religion, rituals, role of nature, roles, soap operas, social security, social class, spatial relations, sports, stereotypes, taboos, trends, values, ways of giving and receiving feedback, and work. This would be, in particular, the case with, but not limited to, language curricula. It is noteworthy that culture resides not in the above elements per se, but in how individuals and groups interpret, use and perceive these constructs (Banks and McGee 1989). We caution that many of the above are complex constructs, and need to be approached with care, with 
knowledge-building and perspective-taking being key parts of the exploration process. A discussion of personal values can help centre discussions. Moreover, it can be helpful to often return to the fact that no cultural construct is likely to be a monolithic symbol embraced by all members of a language community, and that culture is dynamic and therefore constantly changing and hopefully progressing.

More importantly, we argue that if an education system has set itself the mission of offering a multicultural education, and if it wishes to help students develop intercultural competence it needs to move beyond the assumption that this will occur simply through the provision of multilingual education. 'Language fluency is necessary but in itself insufficient to represent intercultural competence' (Deardorff 2014: 1). A definition of core intercultural competences and related learning intentions is also required. These could provide teachers with a focus for course development. They could also support students in reflecting on and building intercultural competence by helping to set and measure progress in achieving related targets. Furthermore, declared curricular intentions related to intercultural competence could help convey instructional intent to parents and other stakeholders, and provide a reference point for course evaluations and improvements.

A major challenge in such a process is that these competences are often not immediately apparent (Meyer 2014). Hence, we make explicit below some intercultural competences in order to highlight the complexities involved in developing intercultural competence and to stress that a more systematic approach is required. At its core, intercultural competence is about perspective-taking. Broadly speaking it consists of 'the appropriate and effective management of interaction between people who, to some degree or another, represent different or divergent affective, cognitive and behavioral orientations to the world' (Spitzberg and Changnon 2009: 9). When intercultural competences are broken down into more tangible elements, they are usually divided into three or four interrelated categories: knowledge, skills, attitudes and values. Values are sometimes subsumed under knowledge and attitudes.

In the knowledge domain, Candelier et al. (2012) propose that students need to know that it is often difficult to distinguish one culture from another, and that a culture is always complex and is itself made up 
of (more or less) different and conflicting or convergent subcultures. This leads to the idea that one can have a multiple, plural or composite identity. In other words, every person forms part of at least one cultural community and many persons form part of more than one cultural community. This seems particularly pertinent in the European schools' context. On a practical level, students need knowledge of some of the characteristics of their own situation and cultural environment. They also need to know some social practices and customs from different cultures, including some norms related to social practices, which are specific to certain social, regional and generational groupings. Cultural practices vary across and within generational, regional and social groupings. Students also need to know how culture and identity influence communicative interactions. Finally, they need to know strategies that one can use to resolve intercultural conflicts, such as knowing that the causes of misunderstanding must be sought out and clarified in common. In addition, Gudykunst (1993) proposes that students also need knowledge of alternative interpretations so they can weigh them against each other. They also require knowledge of 'oppressions' including 'intersecting oppressions' (e.g. class, gender, race, religion) (Spitzberg and Changnon 2009: 11).

In the attitudinal domain intercultural competences include: viewing difference as a learning opportunity; being prepared to be considered as an 'outsider'; being open (and mastering one's own eventual resistances) to what seems incomprehensible and different; having the will to suspend one's judgment, acquired representations and/or prejudices; considering all languages as equal in dignity; being disposed to plurilingual and pluricultural socialisation; seeing loans from cultures as contributing to cultural enrichment; being prepared to experience a threat to one's identity; being able to assume a critical distance from information and opinions produced by media, common sense and one's interlocutors about one's own community and other communities; being willing to construct 'informed' knowledge or representations; being willing to establish a relationship of equality in plurilingual and pluricultural interaction; and being open and empathetic towards the unfamiliar, be that linguistic or cultural (Candelier et al. 2012).

The skills domain includes the ability: to recognise and identify cultural specificities, references or affiliations; to view and interpret the world from 
other cultures' points of view and to analyse the cultural origin of different aspects of communication; to analyse the cultural origins of certain behaviours, and analyse misunderstandings due to cultural differences; to tolerate ambiguity and view it as a positive experience; to use formulae of politeness appropriately in diverse cultural contexts; to identify, analyse and reduce ethnocentrism; to compare one's own non-verbal communication practices with those of others and to explore one's own prejudices; to recognise and name cultural prejudice; to build well informed and structured arguments about cultural diversity; and to have conflict resolutions skills (ibid.). In addition, Spitzberg and Changnon (2009) argue that intercultural competence requires skill in identifying and challenging discriminatory acts, as well as skill in assessing intercultural performance.

In the values domain, intercultural competence includes valuing human dignity and human rights, cultural diversity, democracy, justice, fairness, equality and the rule of law (Council of Europe 2016). Deardorff (2013) adds to this list by suggesting that global intercultural competence includes: adaptation, cultural humility, listening, relationship building, respect, seeing from multiple perspectives, and self-awareness. Stressing the challenges of applying some of these competences, Spitzberg and Changnon (2009: 35) point out that as one seeks to adapt to diverse cultural situations, this should not 'result in excessive compromise of personal identity'. As people often draw their energy for action from the values and attitudinal domains it is these domains that fuel the implementation of knowledge through the use of mechanisms and the application of skills (Mehisto 2015).

This detailing of intercultural competences has sought to bring weight to the argument that the European Schools System could benefit from making explicit the intercultural competences it is seeking to develop. We suggest that the construct of intercultural competence is so complex it is not likely to be well understood across the European schools if curriculum documents do not make reference to it and draw it out in greater detail through related intended learning outcomes. Furthermore, without distilling these competences in one document and/or integrating some of these competences into curricula it is difficult to understand how leadership in the development of these competences could be assumed. It is difficult to support people in reaching a target if the target is unclear. 


\section{Language Curricula}

The English, French and German L2 European schools' secondary level language syllabuses, with the exception of the very short L2 French and English syllabuses, appear light on content and heavy on language learning (Leaton Gray et al. 2015). This runs counter to current professional discourse on effective language teaching. Martel (2016: 107) argues that a language class should not be 'a thinking-light subject' focussed primarily on the learning of grammatical structures, and that language teachers choose content and tasks that are 'thought-provoking'. When content and tasks in language classes 'are not just an excuse to increase a learner's overall linguistic repertoire', but are also focussed on the 'acquisition of new knowledge as well as the completion of specifically targeted tasks designed to deepen students' understanding', capacity to think critically and learning of 'non-linguistic content', students and even teachers have much to gain (Cammarata 2016: 124).

Language classes that incorporate new meaningful content expose students to a wider range of topics and contexts than would be the case in a standard language class. Content-based language teaching uses more functions, genres, and registers of language and vocabulary (including terminology, phraseology and other formulaic sequences, collocations, connectives, phrasal verbs). By extension this will help students build their capacity to produce a deeper and wider range of language output (Cumming and Lyster 2016). Importantly in the European schools' context, where students need to use their L2 and in some cases their L3 as a medium for content learning, content-rich language classes would likely provide them with exposure to and practice in using the general academic language that is needed in several content subjects. However, a review of the European schools' secondary level English, French and German L2 language syllabuses reveal that these language classes could do more to help prepare students for those content subjects they are expected to study through their L2 (Leaton Gray et al. 2015). More specifically, they could further incorporate meaningful activities that require the use of core academic functions common to many content subjects such as: analysing, classifying, comparing, contrasting, explaining causes and consequences, evaluating, hypothesising, inquiring collaboratively, justifying, 
persuading, separating fact from opinion, solving problems, synthesising and verifying.

A further benefit of content-based language instruction as opposed to standard language teaching is that curricular content becomes more meaningful and this creates 'a genuine immediate need to learn the language', which in turn engages and motivates students to learn language (Lightbown and Spada 2013: 193). The more meaningful the content the more likely students are to recall the related language. Increased recall can boost student confidence in using the language. As a by-product, anxiety related to language use and learning is usually reduced. As an added benefit to content-based instruction in language classes, teachers report finding their own work more motivating (Davison and Williams 2001). Importantly when language classes focus on integrating meaningful content and encouraging students to think critically about that content, the students become more effective critical thinkers in reference to both content and language. This implies avoiding situations where language teachers focus only on the language being learned and avoid substantive analysis of the content used to carry the language (Cammarata et al. 2016).

European schools' secondary level students have an immediate need to use their L2 (in some cases their L3) to navigate, to think critically about and to learn content in geography, history, and economics classes. This reality places an extra responsibility for language learning on the L2 and L3 language teachers. It is reasonable to expect language curricula and teaching to adapt to this reality. This would mean adapting L2 and L3 language curricula so as to teach elements of language in a sequence that is partly determined by the content students are learning through their L2 and/or L3. L1 language teachers would also be expected to play a supportive role in helping students develop generic language skills and high levels of literacy. Furthermore, as there is a general consensus that content-based language learning leads to greater language learning, it is also reasonable to expect that language classes engage students with new and meaningful content in addition to new language (Brinton et al. 2011; Tedick and Wesely 2015).

There are several ways of incorporating meaningful content into language classes. As we discussed in the previous section on intercultural competence, in particular considering the centrality of culture and inter- 
cultural competence in the European schools' discourse, it would be logical to integrate more substantive cultural content and the development of intercultural competences into language curricula. This would be the case even with curricula such as the Finnish L4 syllabus, which has sought to unpack Finnish culture in relative detail. In addition, language curricula could use topics and materials that are compatible with what is being learned in content classes. This content-compatible material would not be essential for students to meet the intended content learning outcomes of their content classes, but help students develop a command of the language needed to meet those content outcomes. Language teachers would need to feel comfortable in using and teaching these content compatible topics and materials. These are generally integrated into language classes through cooperation between content and language teachers. Another option is to encourage enquiry-based learning where students research a topic both in their L1 and L2 and report on it in their L2. Enquiry learning places part of the onus on the student to seek out and use needed language, whilst peers and teachers would then be called on to provide corrective feedback.

Reagan (2016) suggests that language teachers should use critical pedagogies in language classes; a pedagogy focussed on reducing inequalities and injustices. He proposes that they explore with students 'fundamental questions about knowledge, justice, equity in their own classroom, school, family and community'. Reagan (2016: 174 citing Wink 2000) contends that by having students engage with 'understanding their place and responsibility within' the world in order to improve it, they become truly engaged with thinking critically about content and language that reaches beyond the walls of the classroom. He sees critical pedagogy as a way of making content and language learning 'count' and thus memorable.

A major exercise in coherence making would need to take place if the above-suggested changes were to be incorporated in the European schools' language curricula. Curriculum documents would need to be revised through a stakeholder inclusive process. The development of L2 and L3 language curricula would to some extent need to be aligned with the curricula of those subjects students are studying through their L2 and /or L3. A discussion would be required on the teaching practices that support learning in bilingual education contexts. For example, in situations where 
students are not fluent speakers of a given medium of instruction, Gibbons (2009) argues that when planning for a curriculum of intellectual quality, there is a need to maintain a relentless double focus on building a high-challenge, high-support learning environment. Also, assessment procedures would need to be adjusted to make sure they support the achievement of curricular goals. Finally, as moving to a content-based approach in language classrooms is likely to constitute a major shift in practice, it is best to assume that this change will not be self-evident to students, their parents, language teachers, content teachers or school administrators. Key stakeholders would need to have their attention drawn to the fact that language classes now support not only language learning, but content learning and critical thinking and that students need to maintain a triple focus in language classes on language, content and precision of thought. This would require additional effort from, and the use of effective learning strategies by, students. Teachers would likely require professional development. Finally, this proposed shift also calls for cooperation with content teachers and a 'language-sensitive' approach to teaching in content classes (Wolff 2011).

\section{Content Subject Curricula}

The primary intent of teaching some subjects in the European schools through the students' L2 is that students become more proficient in that L2. In other words, in addition to teaching students content, those subjects taught through the students' L2 are being used as a vehicle for language teaching and learning. However, the generally longstanding European schools' subject syllabuses do not include explicit language objectives. Neither do new syllabuses such as the Geography Syllabus (4 period course Year 6/7) and ICTC Syllabus (S1-S3 ICT). This leaves the impression that language learning in content classes is seen as largely incidental. Language that needs to be learned is rarely drawn out in curriculum documents, and when this is done, it is at the level of vocabulary (e.g. new Geography syllabus). Subject specific terminology can be considered only the tip of the iceberg in terms of the academic language of Geography that must be learned by students. The syllabuses for content 
subjects to be taught through the L1 also lack well-defined language objectives.

Language plays a crucial role in learning. ' [L]anguage, communication and cognition [...] are mutually inextricable. Cognition and language create each other' (Ellis and Robinson 2008: 3). From a Vygotskian perspective, language is not simply a tool for communication, it is a tool for creating knowledge through 'socially shared cognition' (Kasper 2008: 59), and for honing thinking (Vygotsky 1978). Thus, thinking does not simply occur in a vacuum, but requires input from and interaction with others. If language assumes a double function, 'as a means for communication and a tool for thinking', it is also possible to view both interactions in the L1 and L2 as tools for learning and as competences in their own right (Kasper and Rose 2002: 33). Students learning through their L1 need support in order to master academic language, which as Bourdieu and Passeron (1994: 8) point out 'is nobody's mother tongue'. Academic language includes the language needed for learning and imparting new skills and knowledge, and for discussing abstract ideas and building conceptual understanding (Chamot and O'Malley 1996). It is much more complex and its corpus is over ten times that of social language ( $\mathrm{Hu}$ and Nation 2000). Moreover, as a command of academic language underpins student achievement it is particularly important that this language be taught explicitly (Murphy 2016). In bilingual education, one is faced with the particular difficulty of helping students with limited L2 language skills to learn both academic language and use that language to think about and analyse complex content concepts.

Taking a language-sensitive approach to teaching content subjects is considered a hallmark of bilingual education. Many researchers and practitioners working in bilingual education or with students who are not yet proficient in the language of instruction call for the concurrent and integrated teaching of content and language (Echevarria et al. 2008; Gibbons 2009; National Academies of Sciences, Engineering and Medicine 2017). The principle that all content teachers also assume responsibility for language teaching is also at the core of the Content and Language Integrated Learning (CLIL) movement, a frequently used term to describe diverse types of additive bilingual education (cf. Genesee and Hamayan 2016). In addition, in education systems teaching primarily through a national 
or regional language, the languages across the curriculum movement, the start of which Parker (1985) dates to 1966, essentially argues for the use of a language-sensitive approach to teaching. The seminal $A$ Language for Life report maintains that language plays a central role in mediating learning and therefore, that every content teacher is also a language teacher (Bullock 1975). The report's primary conclusion is that secondary schools should foster language learning across the curriculum. These principles continue to be held in high esteem by experts in the field, the curricula of several nations and supranational bodies such the Council of Europe (Vollmer 2006).

The consequences of not taking a language-sensitive approach can be significant. Considerable evidence suggests that if students are not fully proficient in the language of instruction and educators do not support the learning of academic language, and if oral and written language instruction is not integrated into content classes, content learning and academic achievement can in general suffer (National Academies of Sciences, Engineering and Medicine 2017). In addition, Johnstone (2002) points to a tendency for bilingual education students' L2 language development to reach a plateau where certain gender, syntax and morphological errors become fossilised, and the students' language use may not be appropriate to context (e.g. they may use an informal register in a formal context). This is a level of language where students can communicate with relative ease, but where their language usage is still far removed from that of a native speaker. In these cases, the students and the teachers appear to be more motivated by content learning than language learning. Lyster (2007: 42-43) points out that 'language features learned in isolated grammar lessons may be remembered [...] during a grammar test,' but that they are less likely to be retrieved during content classes. To prevent fossilisation of errors Lyster (ibid.) proposes maintaining a dual focus on content and language by counterbalancing content-based and form-focused instruction and doing this across the curriculum.

There is some evidence that European schools' students have been able to achieve results that are superior to Canadian bilingual education students' results, and this sometimes in shorter periods of time (Genesee and Baetens Beardsmore 2013). Housen (2002a, b) studied the L2 achievements of European schools' students in three different countries. He reported that despite having little out-of-school support for learning the 
L2, students produced 'grammatically accurate and lexically precise sustained discourse in an L2' (Housen 2002a: 213). Housen stressed that these levels were only achieved at the end of secondary schooling.

As we have already suggested, a concrete manifestation of a languagesensitive approach to teaching content subjects would, at the very least, be reflected in curriculum documents through the inclusion of language objectives. Without language objectives, it is difficult for teachers to plan for student learning. Clear intended language objectives not only provide a focus for planning lessons, but they also facilitate course development and the choice, adaptation and/or creation of learning resources.

Moreover, clear and concise language objectives explain to learners what is expected of them. If language-learning expectations are not clear, it is difficult for a student to see his or her own language-learning path, to assess progress and to plan for further language learning. Objectives are considered fundamental to building and maintaining learner motivation (Gardner 1985; MacIntyre 2002). They have the potential of supporting learner autonomy. Legenhausen (2009) asserts that in a classroom fostering autonomy students participate in the planning. They negotiate decisions pertaining to the learning process for which they will be held accountable. They do their planned work undertaking the necessary research. Finally, they evaluate both the learning process and their progress. Language objectives are a key mechanism for students and teachers in managing the language learning process in a thoughtful and explicit manner.

Content objectives all involve language; however, the emphasis in those objectives is primarily on content learning. Language objectives primarily focus on one or more of the following four aspects of language (Mehisto and Ting 2017):

Language Awareness These objectives focus on the use of academic versus social language and on grammatical conventions. Students are able to:

- maintain a consistent and precise use of terminology and other scientific vocabulary throughout a written text;

- organise a written report under the following headings: purpose of the experiment, hypothesis, variables and constants, equipment, method, findings and conclusions. 
- use correctly the phraseology and terminology for a given unit found in the class language bank;

- recognise and defend against the use of emotional language; and

- identify the language of subjectivity.

Communicative Competence These objectives focus on the nature of communication such as whether students are using short answers versus a well-developed line of reasoning and the richness or paucity of language being used. Students are able to:

- support their opinion with a two-point explanation;

- partake actively in classroom discussions and group work using the L2;

- manage their voice (volume, intonation, enunciation, tone) when making a presentation;

- use a rich diversity of language to elaborate and clarify;

- create detailed and easy-to-follow instructions for conducting diverse tasks (e.g. an experiment, a line of enquiry).

Language Learning Skills These objectives are focussed on developing meta-cognitive and meta-linguistic awareness that allow students to take better charge of their own language learning. Students are able to:

- read a text for different purposes (e.g. consistent flow of ideas, grammar, spelling);

- use an L2 thesaurus to enrich language use in their written work;

- skim long (and complex) texts to decide whether a source is suitable for further study;

- make research notes in an organised fashion that allows them later to find relevant information quickly;

- (a) create successive draft versions of a text; (b) test the intelligibility of their text based on the reactions of others; and, (c) use what they have learned to correct and improve their text.

Cross-Cultural Communication These objectives focus on the previously discussed construct of intercultural competence with a particular focus on knowledge, skills, attitudes and values. Students are able to: 
- use formulae of politeness appropriately;

- suspend immediate judgement whilst analysing unfamiliar situations when reading about people from $X$ culture

- compare their own non-verbal communication practices with those of people from other cultures;

- and demonstrate deep order perspective-taking (based on Candelier et al. 2012; Deardorff 2013).

Just as is the case with making a shift to content-based instruction in language classes, taking a language-sensitive approach to the teaching of content subjects implies a major shift in practice. As we have discussed above, a shift to language-sensitive teaching in content subjects will have implications for curriculum and course development, teaching and learning practices, teacher cooperation, assessment, professional development plans, and for management and leadership practices.

\section{Languages of Instruction}

In a bi-/tri-/multilingual education environment that seeks to foster additive bi-/tri-/multilingualism, the language used to teach any given subject, as long as each language is used to teach some high status subjects, is a secondary issue when compared with the quality of teaching and learning practices. There is no subject that one could say with absolute certainty that it should be taught through the L2 or L3. Every subject being taught through the L2 or L3 could be considered as having its own challenges and benefits. In general, a deciding factor of the language of instruction is the availability of teachers (Ruiz de Zarobe 2015). From the students' perspective, their preferences for a given language of instruction may be motivated by where and in which language they wish to undertake their post-secondary studies.

The core principles of ensuring that as many students as possible receive their education in their L1, that all pupils undergo the study of some subjects in their L2, and that all students study an L3, and that those students without language sections at least receive language classes in their L1 have served the European schools well. These structural 
arrangements are a manifestation of the education system's and its stakeholders' values; their respect for mother tongue, multilingualism and multiculturalism. Any attempt to use arguments such as the generally higher than average academic achievement of SWALS to reduce the number of language sections would strike at the heart of the European schools' core values.

However, despite the general high level of achievement of SWALS, there are two primary areas of concern: the extra challenges these students face especially when having to study subjects through their L3 or L4, and how well prepared they will be to undertake post-secondary studies in their L1. SWALS can find themselves in mixed language groups (i.e. in Art, ICT, Music and Physical Education). In these circumstances decisions about pedagogy and which language or languages of instruction will be used for teaching, learning and assessment take on a particular importance. It is possible for European schools' students in S1 to find themselves in a subject such as ICT that is being taught in their L3 whilst they are only beginning to study their L3. This begs the question as to what extent students' needs vary in mixed language groups due to language knowledge, and how learning is being scaffolded and differentiated individually for students who are learning through their L2 or L3. We are unaware of European schools being provided with any direction other than having English, French or German being prescribed as a medium of instruction for these subjects. In addition, we are unaware of how European schools' teachers, teaching mixed language groups, are trained, and what expectations are placed on them regarding differentiation and 'multilingual education'. Finally, should SWALS wish to return to their country of origin to undertake post-secondary education, it is debatable whether their L1 language classes alone would allow these students to develop sufficient proficiency in the academic registers of their L1 to be prepared for continued study through that language.

One of several possible ways of helping to address the language needs of SWALS when they are studying subjects through their L3 or L4, which can have the added benefit of helping them to prepare for post-secondary studies, is to use 'translanguaging' in one and the same subject (Williams 1996). Translanguaging involves speaking, listening, reading and/or writ- 
ing about a topic in one language, and then speaking or writing about it in another. In translanguaging 'both languages are used in an integrated and coherent way to organise and mediate learning' (Baker 2011). The focus of translanguaging is on meaning making and gaining a deeper understanding of subject matter content through two languages. It avoids any overuse of the L1 in classes taught through another language that might in the long-term undermine the learning of the additional language. Translanguaging can also be used as a strategy for having students who are studying most of their subjects through an L2, to gain exposure to $\mathrm{L} 1$ academic language. On a practical level, translanguaging includes activities such as having students: draft an outline of a report in their L1, get feedback from the teacher in their L2, and write the report in their L2; conduct an enquiry that requires the use of L1 and L2 sources when doing their research; and, analyse three texts in two (or if possible three) different languages about an historical event (e.g. three stakeholder perspectives) and then compare that analysis with what they read in a highly respected foreign press report that seeks to offer a balanced overview.

The rising popularity of translanguaging signals a shift from the previously held view that it is important in bilingual education to keep the two languages apart (Heugh 2016). Teachers teaching through the L2 were expected to teach only through the L2. However, in practice teachers may have been more flexible, often using as much L2 as possible and as little L1 as necessary (Little and Boynton 2004). Currently, it is no longer suggested that teachers teaching through the L2 should never or almost never use the students' L1. There is an increasing recognition that languages are interdependent (Cummins 2000) and that it is normal to mix languages when speaking in informal contexts, but essential to be able to separate languages when producing written academic work (Heugh 2016).

Although more research is required on the matter, initial indications are that translanguaging may: lead to deeper conceptual understanding of a topic; help students to better encode learning in memory; and allow for easier retrieval of learning from memory (Baker 2011). Similarly, Genesee and Hamayan (2016: 109) suggest that: 'cross-linguistic connections create meaning; learning in and about one language supports learning in 
and about another language; making the two languages an integral part of lessons reflects the value and high status of both languages; and discussing concepts in more than one language helps to better encode knowledge in the brain for later use.'

Despite the success of the European Schools' teaching of and through languages, their lack of an overall language policy, language objectives in content curricula and a breakdown of intercultural competences, as well as their seemingly content-light language curricula, all imply that the European Schools are under-utilising policy prescriptions and powerful pedagogical principles to drive language and intercultural learning. Moreover, existing European schools' key documents include little or no discussion of or practical guidelines about how summative and formative assessment in a bilingual school fostering multilingualism is unique or different to assessment in a primarily monolingual education context. This is reinforced by the fact that only fleeting mention is made to teaching methodology or other aspects of pedagogy in the minutes of the Working Group 'Organisation of studies in the secondary cycle' or in the Proposal of the 'Organisation of studies in the secondary cycle' Working Group or in our face-to-face meetings during the research project. In addition, whilst the European Schools are showing clear concern for students in particular with regards to the failure and drop out rates, the near absence of discussion about the quality of teaching in relation to dropout rates seems to covertly place the responsibility for these rates on the current organisation of studies and students, but not on teaching. There is currently a need to accord the quality of teaching and in particular student learning considerably more attention on policy and meeting agendas. This could help ensure that the European Schools are first and foremost a learning-powered institution that also understands and takes into account the specificities of bilingual education. In the next chapter, we examine issues of social selection, sorting and segregation in relation to educational practices within the European schools. 
Open Access This chapter is licensed under the terms of the Creative Commons Attribution 4.0 International License (http://creativecommons.org/licenses/ by/4.0/), which permits use, sharing, adaptation, distribution and reproduction in any medium or format, as long as you give appropriate credit to the original author(s) and the source, provide a link to the Creative Commons license and indicate if changes were made.

The images or other third party material in this chapter are included in the chapter's Creative Commons license, unless indicated otherwise in a credit line to the material. If material is not included in the chapter's Creative Commons license and your intended use is not permitted by statutory regulation or exceeds the permitted use, you will need to obtain permission directly from the copyright holder.

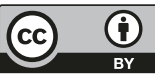

